\title{
Experiment and Simulation Analysis of Micro-type Circular Rod Screw Thread for SUS304 Stainless Steel in Machining Process
}

\author{
Tsung-Chia Chen, ${ }^{1}$ Hao-Wei Ting, ${ }^{1}$ and Cheng-Chi Wang ${ }^{2 *}$ \\ ${ }^{1}$ Department of Mechanical Engineering, National Chin-Yi University of Technology, \\ No. 57, Sec. 2, Zhongshan Rd., Taiping Dist., Taichung 411030, Taiwan \\ ${ }^{2}$ Graduate Institute of Precision Manufacturing, National Chin-Yi University of Technology, \\ No. 57, Sec. 2, Zhongshan Rd., Taiping Dist., Taichung 411030, Taiwan
}

(Received July 5, 2021; accepted September 14, 2021)

Keywords: micro-type circular rod, stainless steel, finite element, screw thread

The main purpose of this study is to analyze the screw thread machining process for microtype circular rods of SUS304 stainless steel. During the analysis, micro-type circular rods with various outer diameters $(1.9,1.94$, and $2 \mathrm{~mm})$, pitches $(0.25 \mathrm{~mm}$ and $0.4 \mathrm{~mm})$, and friction factors $(0.1,0.2,0.3,0.5$ and 0.7$)$ are fabricated. Owing to the micro scale of the thread, the scale factor of the material should be corrected, and finite element analysis is conducted to determine the effect of the pitch and friction factor on the screw threads of the micro-type circular rods during the machining process. The finite element analysis uses a full integration rule to couple the shape function, which is inferred from the 3D tetrahedral element with four corner nodes used in the stiffness matrix. Then, we simulate the comprehensive forming history and determine the stress/strain distribution and thread shape distribution relating to the thread machining process for the micro-type circular rod. A micro-type circular rod screw thread machining die is also designed to carry out an experiment on micro-type thread machining for SUS304 micro-type circular rods. The result is compared with the simulation result to verify the reliability of the analysis method. The difference between the uncorrected material parameters and the corrected microscale dimensions is also analyzed. The corrected material parameters indicate that the maximum principal stress sensed in the experiments increases with the pitch. During the microtype circular rod screw thread machining process, the torque, stress, and strain increase with the increase in the friction factor.

\section{Introduction}

With the advancement of miniaturization in manufacturing, the demand for micro-type parts is increasing. Since the 1980 s, the traditional plasticity machining process has been applied in the micro-forming techniques used to manufacture very large amounts of micro-forming metal components. This technique has been widely used in the miniaturization of parts used in cell phones and medical, mechanical, and digital products. As the micro-forming technique has the advantages of a high manufacturing speed and a low cost, it is especially suitable for mass ${ }^{*}$ Corresponding author: e-mail: wcc@ncut.edu.tw https://doi.org/10.18494/SAM.2021.3530 
production. ${ }^{(1,2)}$ It is therefore a very important technique for the micro type of manufacturing. A brief summary of the historical literature on metal forming is as follows. A 3D finite element analysis was employed by Makinouchi and Kawka in 1994 to simulate a stamping die. ${ }^{(3)}$ In their research, a simulation was conducted to clarify issues that may result in defects during metal stamping to replace the traditional trial-and-error method, with the aim of reducing the likelihood of errors and increasing the production speed of products. In 2002, Engel and Eckstein proposed a sub-millimeter machining process, where the size of two parts being produced during the metal forming was smaller than $1 \mathrm{~mm}^{(4)}$ Because the micro-forming process is subjected to dimensional effects, in addition to reducing the forming load, this process will also affect phenomena such as the surface roughness of the workpiece, the friction force during forming, the flow stress of the material, and the bouncing effect. In 2010, Peng et al. studied the evolution of friction behavior from micro dimensions to macro dimensions and proposed an innovative uniform friction model based on the open/closed lubricant bag theory. Using the newly developed friction model, they conducted a finite element (FE) simulation to analyze the dimensional effect on friction during a ring compression process. ${ }^{(5)}$ In 2013, Chiba proposed a probabilistic method that can be used to estimate the reliability of the forming limit of an anisotropic metal plate with uncertain material properties. He also studied the influence of uncertain material properties on the forming limit curve and the resulting strength. ${ }^{(6)}$

The results of a previous screw thread forming analysis by Domblesky and Feng ${ }^{(7)}$ in 2002 explained the influence of the machining parameters on the material flow and thread profile of a large-diameter blank during an external thread-rolling process. In 2004, Pater et al. proposed a method that can complement the thread-rolling techniques being newly developed for concrete tie securing screws. ${ }^{(8)}$ In the thread-rolling method, two wedge-shaped parts are provided with a special groove that is required for thread formation. Furthermore, they also compared the results of theoretical and experimental research on the formation of new screws. The practical screw forming process comprises screw head flash forging and thread rolling. An innovative machining method including flash-free forging and thread forming as well as the use of the cross-wedge rolling technique in a dual-type configuration has been proposed. ${ }^{(9)}$ In 2006, Kao et al. ${ }^{(10)}$ studied an integrated computer-aided design (CAD), computer-aided engineering (CAE), and computer-aided manufacturing (CAM) system that can be used to form the geometrical structure of a thread-rolling die. In 2011, Huang studied the mini-size screw tapper and thread-milling process for LZ91 magnesium alloy and analyzed the influence of the processing parameters on the forging force and the metal flowing state. He also conducted formability analysis and process parameter analysis using DEFORM software to simulate the mini-size screw tapper and thread-rolling techniques. ${ }^{(11)}$ In 2014, Li studied the effect of micro thread tapping on a thin stainless steel plate (SUS304) to analyze the dependence of the thread tapping quality on the thread tapping torque and the post-rolling area. ${ }^{(12)}$

To address the problem of the sudden breaking of threads when tapping mini-diameter internal threads of a titanium alloy, Pawar and Joshi ${ }^{(13)}$ performed a comprehensive experiment to study the tapping mechanism and the performance of axial vibrating auxiliary tapping (AVAT) and axial torsional vibrating auxiliary tapping (ATVAT) when applied to a titanium alloy. They discovered that, without affecting the thread mass, AVAT and ATVAT can reduce the 
tapping torque, axial force, and temperature compared with those of traditional tapping. In 2017, Oezkaya and Biermann ${ }^{(14)}$ proposed a method to reduce the high cost of developing tapping tools through investigation and experiments. They claimed that the method can be used during the design stage to estimate the relative torque so as to reduce the use of resources and energy as well as the cost.

In this study, we design and set up a micro-type circular rod screw thread machining process for SUS304 stainless steel materials. The thread machining process is analyzed for micro-type circular rods with different pitches. A simulation analysis is also conducted on circular rods with different diameters, thicknesses, and friction factors. We find that the torque and maximum principal stress and strain can be sensed and measured for reference in die design to minimize the number of trial-and-error procedures. Also, a reliable analysis method is proposed, which can be used to improve productivity and optimize the machining process for micro-type circular rod screw threads.

\section{Analysis Method}

\subsection{Simulation analysis}

The metallic plate selected for this research is made of SUS304 stainless steel with a bodycentered cubic (bcc) crystallized structure and special chemical and physical characteristics. It is one of the corrosion-resistant alloy materials normally used in the industrial and medical industries. In this study, we will focus on the elastoplastic deformation with the following hypotheses:

- The screw die and lower die are assumed as rigid bodies.

- All materials have homogeneous properties.

- The elasticity and plasticity strain rate are considered for the strain rate of the material.

- The temperature influence and the existence of internal stress will not be considered during the forming process.

- The materials shall be treated according to the yielding conditions proposed by von Mises, and the plastic flow rule proposed by Prandtl-Reuss shall be followed after the plasticity deformation.

In this study, the simulation is conducted with the DEFORM-3D FE analysis software by considering the screw die as the rigid body and the micro-type circular rod as the plastic body, and all the materials are assumed to be under homogeneous and isotropic conditions. Figure 1 shows the forming process of the screw die and the micro-type circular rod. The screw die tends to engage with the circular rod's surface during the circular rod thread machining process, and the nodes that are in contact with or detached from the screw die must be clearly defined. The node shall be divided into contact nodes and free nodes. The node not in contact with the die will be defined as the free node for which the space coordinate $(X, Y$, or $Z)$ shall be used. The node in contact with the die will be defined with a local coordinate $(\xi, \eta, \zeta)$ according to the right-hand rule. 


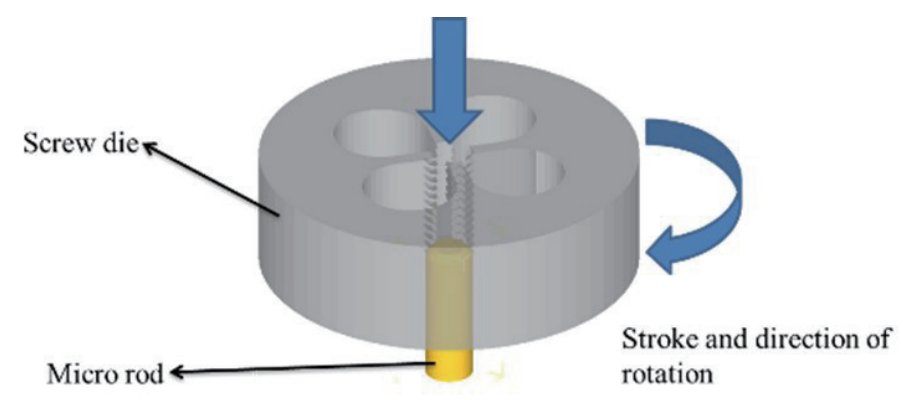

Fig. 1. (Color online) Forming process of screw die and micro-type circular rod.

Table 1

Simulation parameters.

\begin{tabular}{lc}
\hline Material & SUS304 \\
\hline Dimensions of material $(\mathrm{mm})$ & 6 \\
Friction factor $(\mathrm{m})$ & $0.1,0.2,0.3,0.5,0.7$ \\
Pitch $(\mathrm{mm})$ & $0.25,0.4$ \\
Number of grids & 60000 \\
\hline
\end{tabular}

By employing the formula based on the updated Lagrangian formulation (ULF) theory related to the finite deformation and scale factor of modified materials, one will be able to infer step by step the governing equation that will be suitable for the machining process for all types of metals.

When performing the thread tapping simulation with DEFORM-3D, the number of grids will affect the outline of the tapping. The more the number of grids, the longer the time will be required for analytical computation, and the data to be stored for the analytical computation will also become enormous. To achieve a more efficient simulation of thread tapping, normally, the number of grids is set at 60000 . Table 1 shows the simulation parameters.

The plastic flow rule proposed by Prandtl-Reuss and the yielding conditions proposed by Hill are also applied in this study. Regarding yielding condition judgment, the yielding conditions proposed by von Mises are used and applied to isotropic materials, and those proposed by Hill are used in introducing the anisotropic parameters with anisotropic materials considered accordingly. The FE deformation theory and the ULF concept are also combined for creating an increment type of elastoplastic deformation FE analysis mode. Moreover, the shape function inferred from the tetrahedral element with four corner nodes is also employed for coupling to the stiffness matrix. The full integration rule calculation method is also employed to infer the stiffness matrix relating to the tetrahedral element with four corner nodes. When dealing with the friction issue between the screw die and the blank, the modified Coulomb friction law is used. In this respect, the modified Coulomb friction law deals with the friction of the contacting face that is under a discontinued sliding-sticking condition and the linear increment computation is maintained. 
In the meantime, the dimensional effect resulting from miniaturization is also considered, and the traditional material model with the scale factor modification formula is modified for easy numerical simulation by DEFORM. In this way, the software shall be able to display the forming diagram and the stress/strain distribution diagram. It can also display the relationship between the torque and the stroke according to the change resulting from the pitches, friction factors, and circular rod diameters, and display the distribution status of maximum principal stress and maximum principal strain.

\subsection{Scale factor relating to dimensional effect}

As influenced by the dimensional effect, significant errors were found between the FE analysis and the actual product during the micro-forming process such that the traditional material model cannot be used. Thus, a new material model should be developed by considering the dimensional effect. In this plan, the SUS304 is used to carry out the tensile strength test to study the influence of the dimensional effect on the micro-type circular rod. In the meantime, a new micro elastoplastic material model is also developed to compare it with the traditional material model. Therefore, the stress-strain formula for the circular rod and the traditional macro-based material is modified here by the proportional method without considering the material's dimensional effect. As such, the Swift material model is adopted as follows:

$$
\bar{\sigma}=K\left(\varepsilon_{o}+\overline{\varepsilon_{p}}\right)^{n}
$$

where $\sigma$ and $\varepsilon$ represent true stress and true strain, respectively. $K$ and $n$ are the material constants.

In this research, the circular rod diameter $d$ is used as the scale factor for modification. According to the true stress and true strain diagrams obtained from the tensile strength test, the traditional material model should be used if the circular rod diameter is more than $2.2 \mathrm{~mm}$. If the circular rod diameter is less than $2.2 \mathrm{~mm}$, then the modified material model should be used. When using the diameter of a micro-type circular rod as the modifying factor and because the circular rod diameter selected for this research is $2 \mathrm{~mm}$, the traditional material model is modified by proportional methods according to the stress-strain formula established for calculating traditional materials, as provided below:

$$
\bar{\sigma}(d, \bar{\varepsilon})=f M e^{g d}\left(\varepsilon_{0}+\overline{\varepsilon_{p}}\right)^{n\left(h e^{i d}-1\right)},
$$

where $f, g, h$, and $i$ represent the proportional values being modified. Chern et al. ${ }^{(15)}$ showed that the modifying value contained in the aforesaid formula can be effectively resolved by the least squares method. On the basis of the stress-strain relationship obtained in the previous tensile strength test, the values are selected from ten data points for each individual diameter to carry out the calculation. 
To calculate the optimal values for $f, g$, $h$, and $i$, the Levenberg-Marquardt method is used in this research. Such a method is established by combining the advantages of the Newton law and the steepest-descent method. As the search direction selected for the early-stage iteration process is closer to the gradient direction, the iteration is approximate to the direction provided by the steepest-descent method, whereas the later-stage iteration is approximate to the direction provided by the Newton law. By this method, minimal values of $f, g, h$, and $i$ can be obtained as shown in Table 2.

By substituting the proportional values in Eq. (2), the modified formula is provided as

$$
\bar{\sigma}(d, \bar{\varepsilon})=0.7364 M e^{0.3165 d}\left(\varepsilon_{0}+\overline{\varepsilon_{p}}\right)^{n\left(1.0112 e^{-0.01032 d}-1\right)} .
$$

Because the material model with the diameter of a circular rod set at $2 \mathrm{~mm}$ is used in this study for modifying the proportional value, the values of $M$ and $n$ in Eq. (3) should be substituted by using the data obtained from the circular rod with the diameter set at $2 \mathrm{~mm}$. The values of $M$ and $n$ for the stainless steel are $1819 \mathrm{MPa}$ and 0.576, respectively. As such, Eq. (4) indicates the final material model for which the diameter has been modified.

$$
\bar{\sigma}=1340 e^{(0.3165 d)}\left(0.077+\overline{\varepsilon_{p}}\right)^{0.5824 e^{(-0.01032 d)}-1}
$$

\subsection{Tensile strength test}

In this experiment, the stainless steel micro-type circular rod is made of SUS304, and its material parameters are listed in Table 3, which are obtained by considering the scale factors. During the experiment, the tensile strength test is conducted for the $2 \mathrm{~mm}$ micro-type circular rod with the micro-computer tension tester and the load range is below $200 \mathrm{~kg}$. Because the chuck of this machine cannot clamp the micro-type circular rod securely, another set of chucks is added in the testing machine together with another two sets of handheld chucks to clamp the micro-type circular rod in position. The tensile strength test is a convenient method that is

Table 2

Proportional values for modification formula.

\begin{tabular}{cccc}
\hline$f$ & $g$ & $h$ & $i$ \\
\hline 0.7364 & 0.3165 & 1.0112 & -0.01032 \\
\hline
\end{tabular}

Table 3

Mechanical properties and material parameters of SUS304 stainless steel.

\begin{tabular}{lcccccc}
\hline Material & $E(\mathrm{GPa})$ & $v$ & $\sigma_{y}(\mathrm{MPa})$ & $K(\mathrm{MPa})$ & $n$ & $\varepsilon_{0}$ \\
\hline SUS304 & 207 & 0.3 & 316 & 2518.5 & 0.576 & 0.077 \\
\hline
\end{tabular}

$E$ : elastic coefficient; $v$ : Poisson's ratio; $\sigma_{y}$ : yielding stress 
widely used. Many basic mechanical properties can be acquired when the material is subjected to strengthening and axial load during the test. The stress-strain curve is determined during the test in order to analyze the properties of the material, such as the tensile strength and the elasticity limit. Because the length and diameter of the tested material (i.e., micro-type circular rod) are too small such that it cannot be held in position easily and the size of the test piece is also beyond the specifications established for the standard test piece, markings are made at 10 $\mathrm{mm}$ from both ends of the micro-type circular rod for using the stretching positions. By doing so, the chucks required for the machining are secured to the upper and lower positions of the stretching machine by the screw fastening method, and then the micro-type circular rod is locked in position with the handheld chuck. As the next step, the machine stretching speed is set at $2 \mathrm{~mm} / \mathrm{min}$ for carrying out three rounds of tensile strength test for the micro-type circular rod to obtain the desired stretching value, whichever is the largest. Then, such value is translated to the stress-strain diagram in order to proceed with the analysis.

\subsection{Analytical steps}

The analysis procedure includes nine steps as shown in Fig. 2.

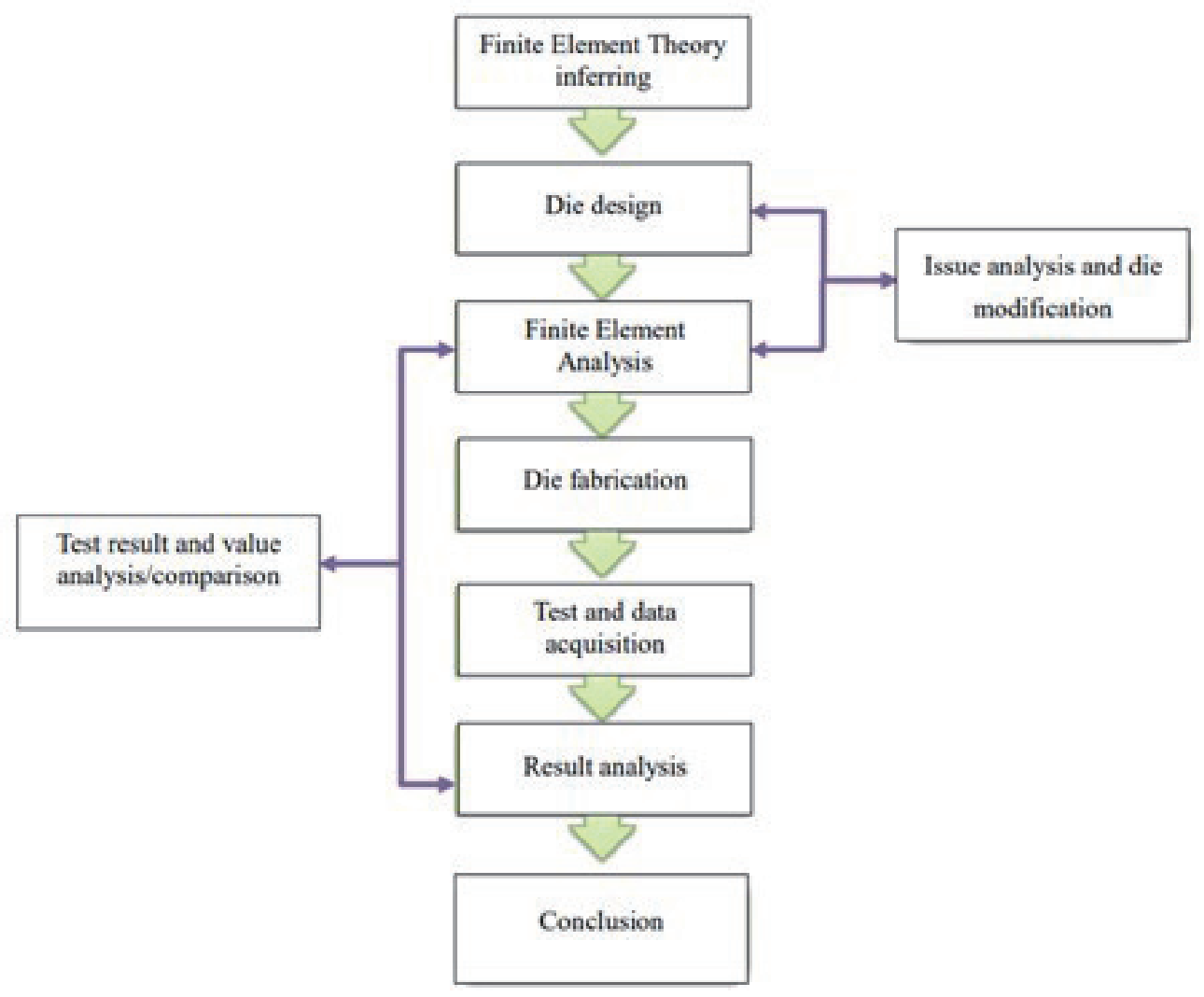

Fig. 2. (Color online) Flow chart of analysis procedure. 


\section{Experiment Verification and Analysis}

\subsection{Torque comparison for test and simulation}

Figure 3 shows comparisons between the experiment and the simulation for the relationship between torque and pitch stroke displacement. Assume that the friction factors are set as 0.2 and 0.3 for carrying out the comparative verification with the experimental results. As indicated in the figure, when the friction factor is 0.3 (i.e., $m=0.3$ ), the curve of the torque resolved from the simulation is closer to that in the experiment. Therefore, the friction factor of 0.3 is selected for the simulation analysis described in the following study, and the screw thread forming process is analyzed for micro-type circular rods.

\subsection{Sensing the tooth shape and comparing with the experiment and simulation}

To determine the difference in the accuracy between the experiment and the simulation being conducted in this research, an optical microscope is used to determine the difference in tooth angle and tooth height of the product and to study the difference between the models used during the experiment and the simulation. The comparison of the thread shape required for the experiment and the simulation is shown in Fig. 4. The tooth angle sensed for the simulated model of $\mathrm{M} 2 \times 0.25$ is $60.431^{\circ}$ and that sensed during the experiment is $60.552^{\circ}$, presenting an error of $0.2 \%$. The height difference for the simulated tooth is $0.06 \mathrm{~mm}$ and that sensed during the test is $0.065 \mathrm{~mm}$, presenting an error of $7.629 \%$. The tooth angle sensed for the simulated model of M2 $\times 0.4$ is $60.987^{\circ}$ and that sensed during the experiment is $60.421^{\circ}$, presenting an error of $0.937 \%$. The height difference sensed for the simulated tooth is $0.039 \mathrm{~mm}$ and that sensed during the experiment is $0.036 \mathrm{~mm}$, presenting an error of $8.333 \%$.

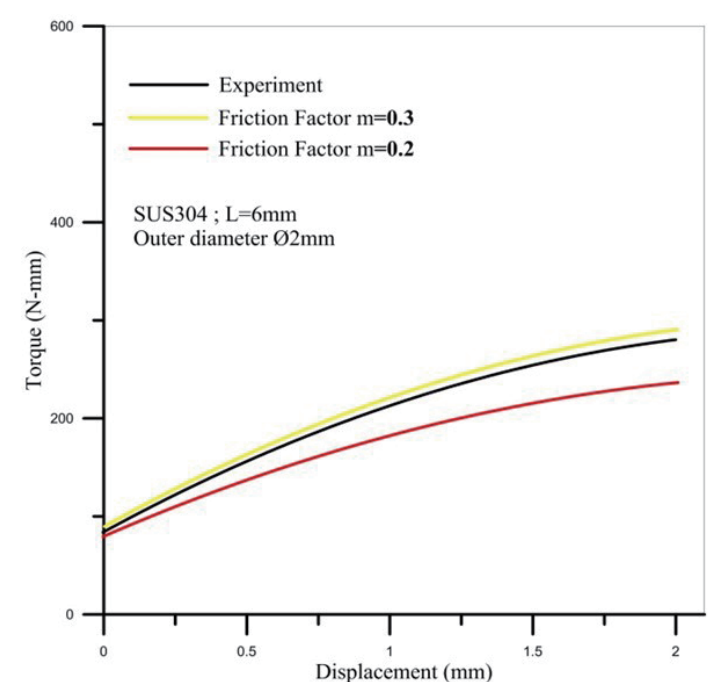

(a)

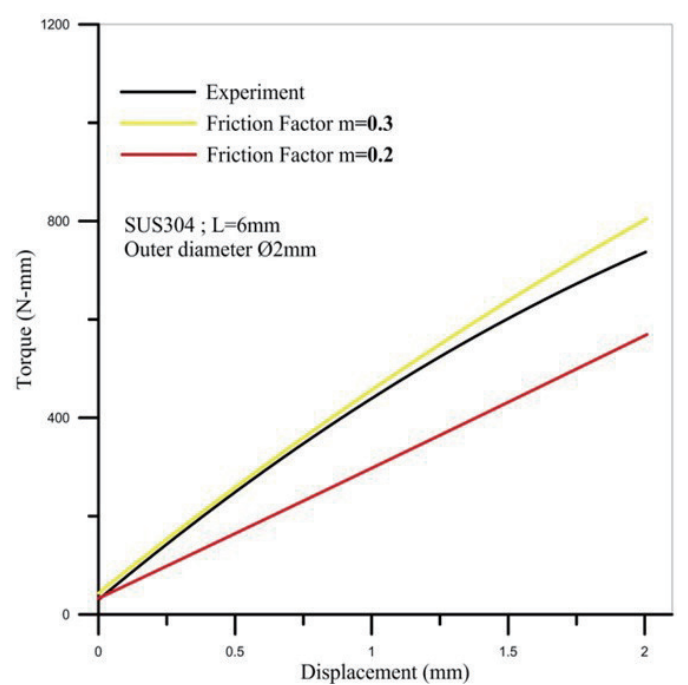

(b)

Fig. 3. (Color online) Relationship between torque and displacement with different friction factors and experiment: (a) $\mathrm{M} 2 \times 0.25$ and (b) $\mathrm{M} 2 \times 0.4$. 


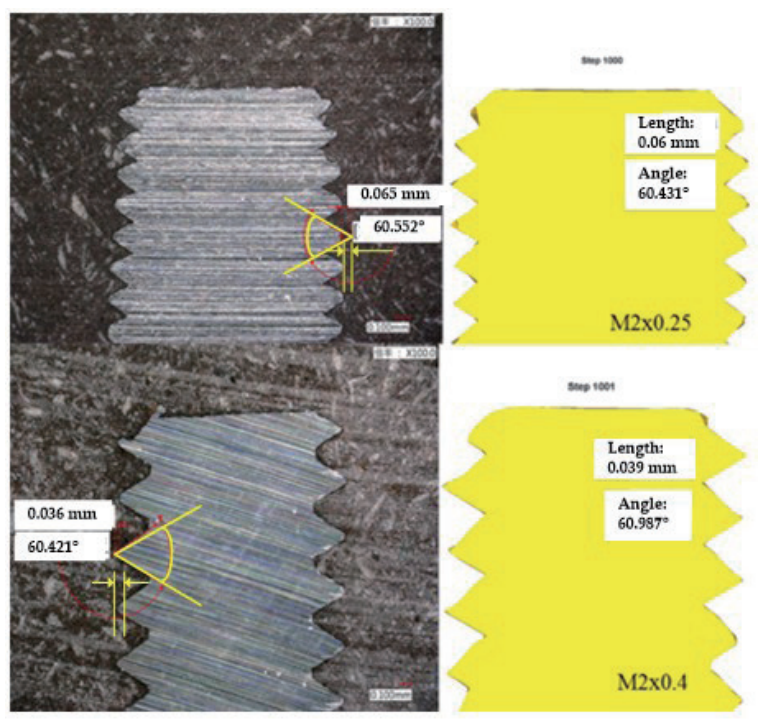

Fig. 4. (Color online) Comparison of thread shape between experiment and simulation.

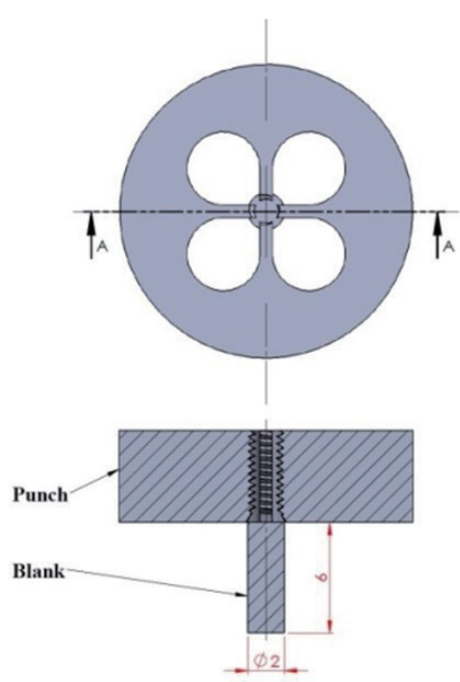

(a)

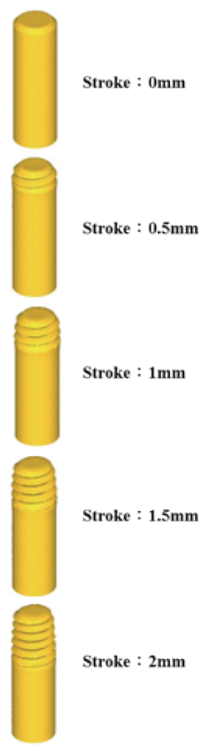

(b)

Fig. 5. (Color online) Forming process: (a) positions of screw die and blank and (b) process.

\section{Results and Discussion}

\subsection{Forming process}

During the simulation, the pitch values are 0.25 and $0.4 \mathrm{~mm}$, the friction factors are $0.1,0.2$, 0.3, 0.5, and 0.7, and the circular rod diameters are 1.9, 1.94, and $2 \mathrm{~mm}$. Figure 5(a) shows the die and blank position layout for the screw die, and Fig. 5(b) shows the five-stage geometric forming process relating to the micro-type circular rod screw thread forming. 


\subsection{Comparison of torque}

Figure 6 shows the relationship between the screw die torque and the pitch stroke displacement with the modified scale factor and traditional model. As shown in these figures, the screw die torque increases rapidly as soon as the screw die comes into contact with the micro-type circular rod and because the screw die pushes against the circular rod during the downward rotation. The results indicate that the screw die torque increases with increasing pitch for $\mathrm{M} 2 \times 0.4$.

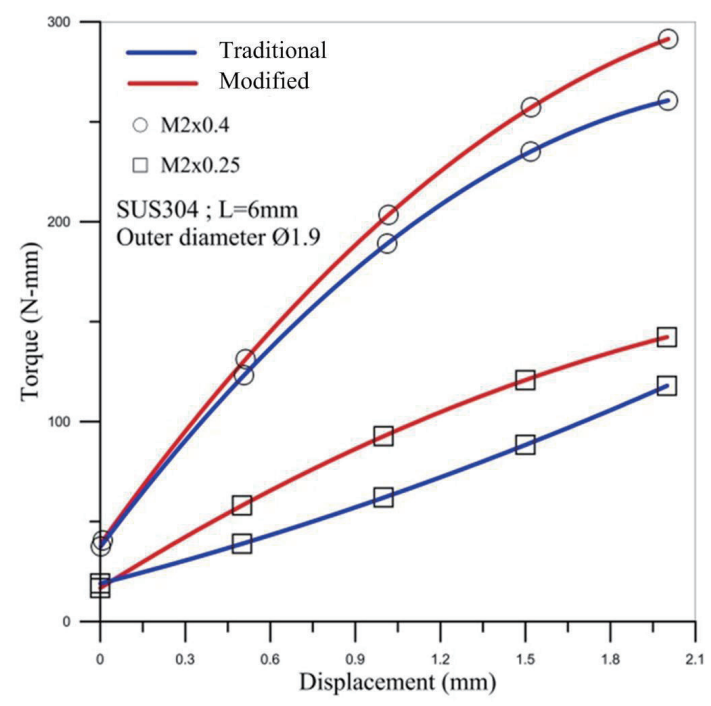

(a)

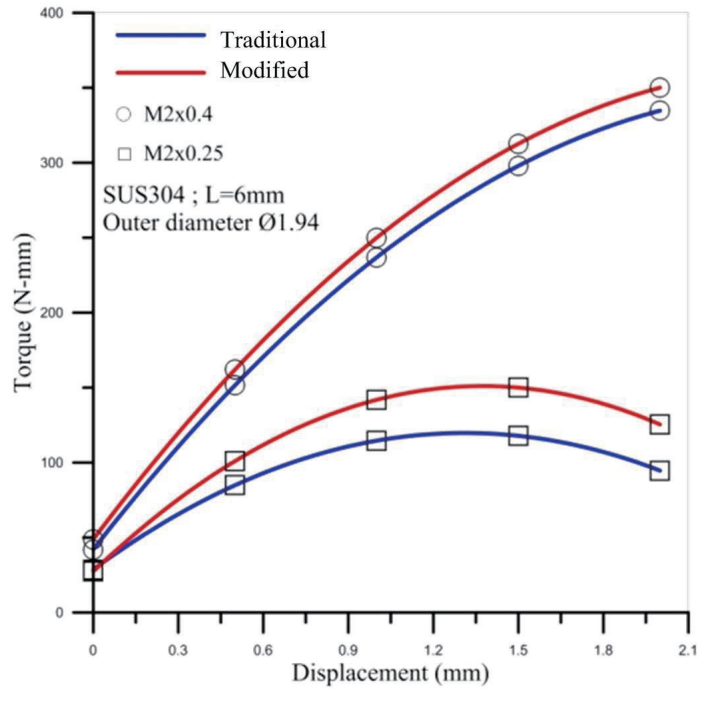

(b)

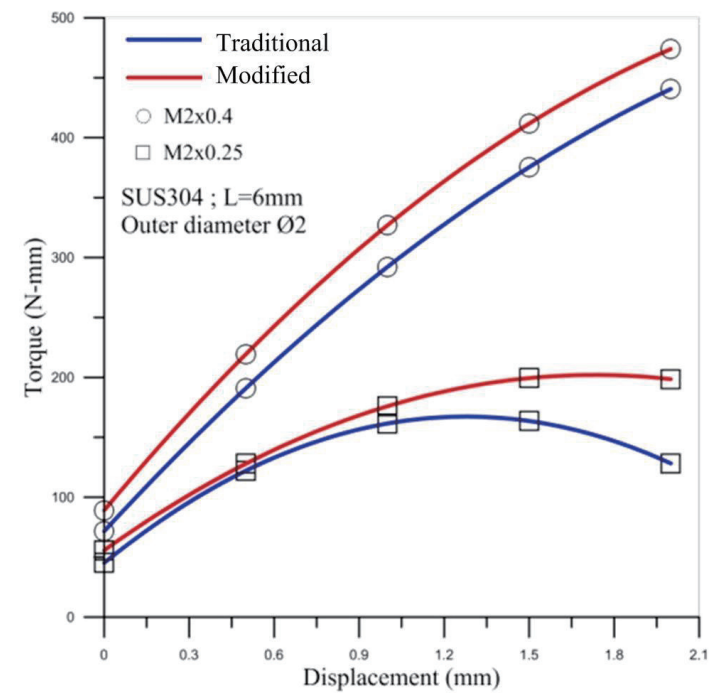

(c)

Fig. 6. (Color online) Relationship between torque and pitch stroke displacement: (a) Ø1.9 mm, (b) Ø1.94 mm, and (c) $\varnothing 2 \mathrm{~mm}$. 
Figures 7 and 8 show the relationship between the screw die torque and the pitch stroke displacement under different friction factors. When the friction factors are changed during the screw thread machining process for the micro-type circular rod, the screw die torque will increase along with the increase in the friction factor.

\subsection{Difference of stress and strain}

Figure 9 shows the relationship between the outer diameter and the maximum principal stress in which the maximum principal stress is presented in the micro-type circular rod thread

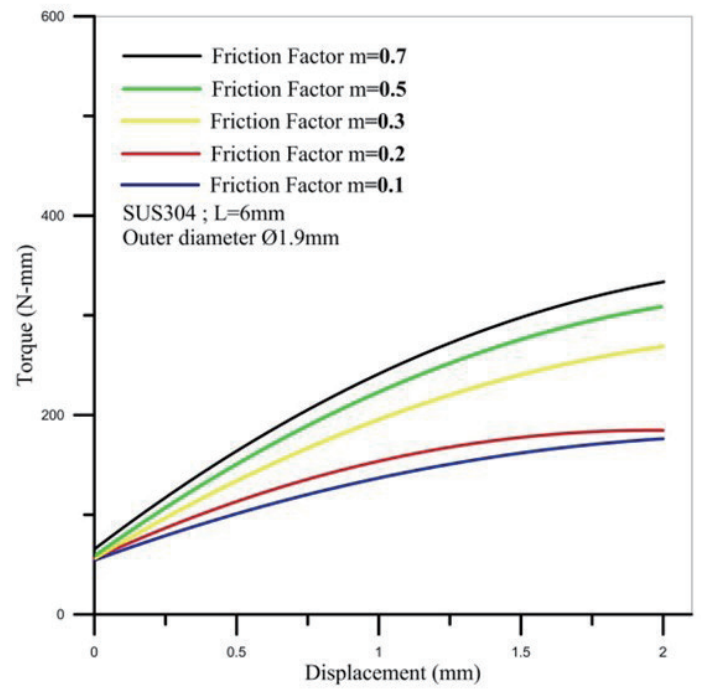

(a)

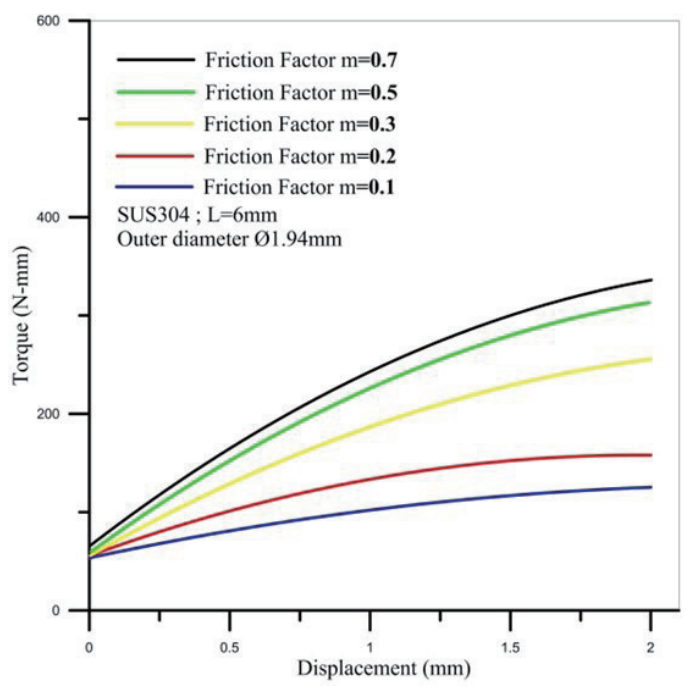

(b)

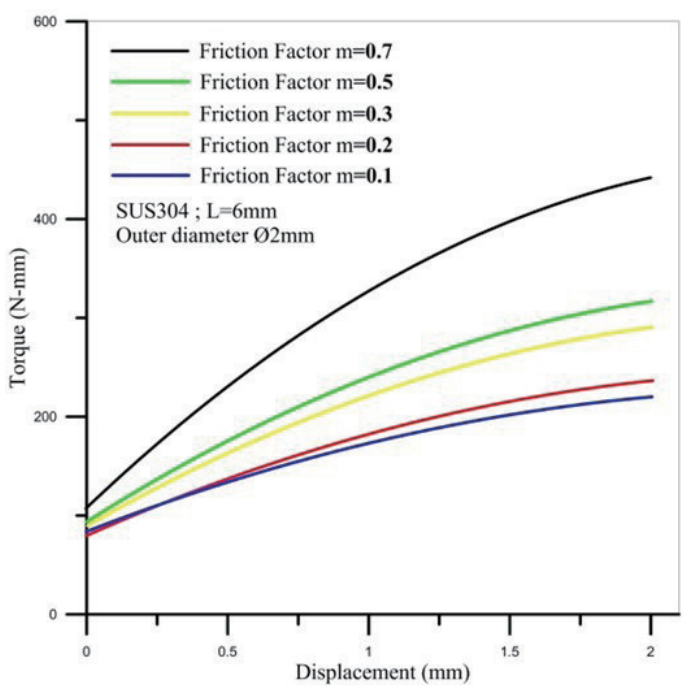

(c)

Fig. 7. (Color online) Relationship between torque and pitch stroke displacement for M2 × 0.25: (a) Ø1.9 mm, (b) $\varnothing 1.94 \mathrm{~mm}$, and (c) Ø2 $\mathrm{mm}$. 


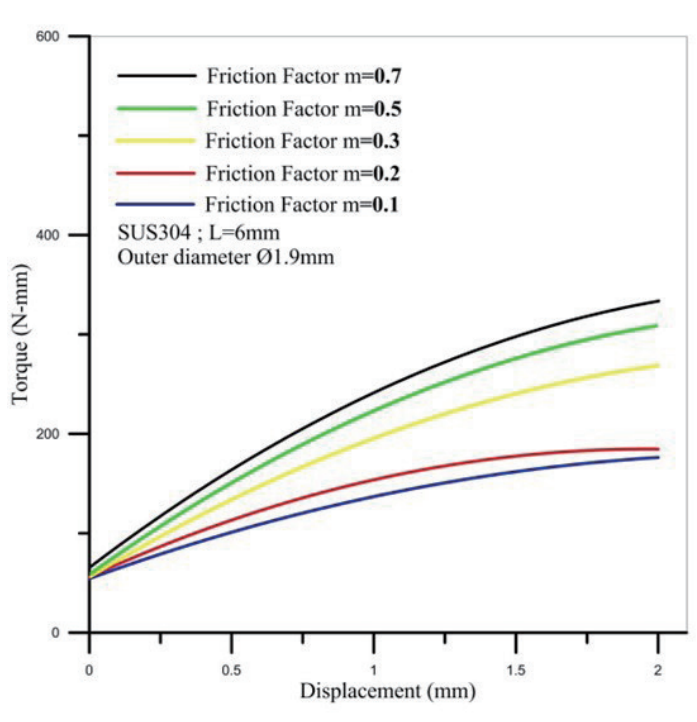

(a)

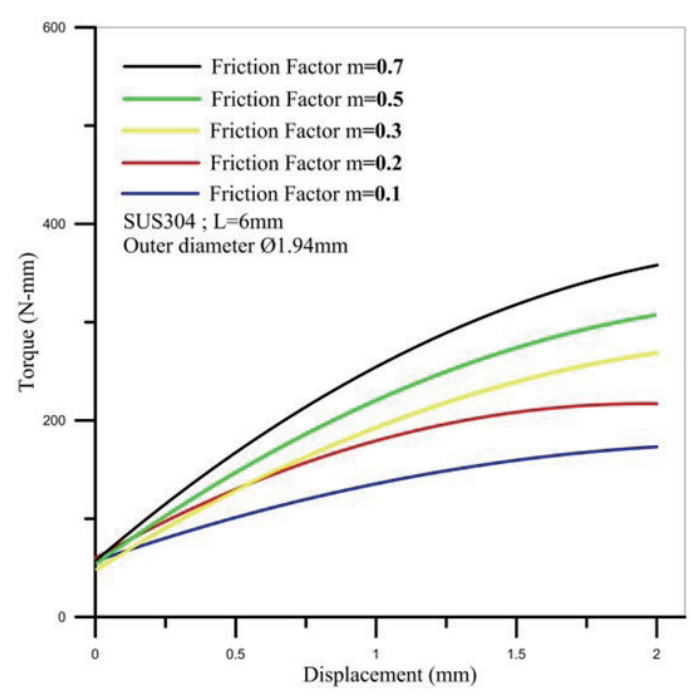

(b)

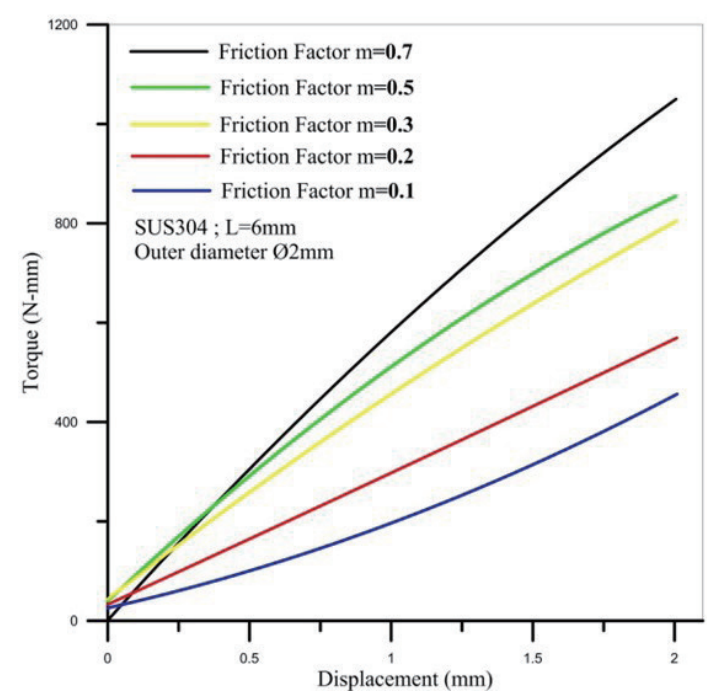

(c)

Fig. 8. (Color online) Relationship between torque and pitch stroke displacement for M2 $\times 0.4$ : (a) $\varnothing 1.9 \mathrm{~mm}$, (b) $\varnothing 1.94 \mathrm{~mm}$, and (c) Ø2 $\mathrm{mm}$.

forming area. Figure 9(a) shows the $0.25 \mathrm{~mm}$ pitch that will be used to execute the thread tapping for the circular rods with the outer diameters of 1.9, 1.94, and $2 \mathrm{~mm}$, the maximum principal stresses of which are 22800, 23100, and $30100 \mathrm{MPa}$ when considering the modified scale factor, respectively. Figure 9(b) shows the $0.4 \mathrm{~mm}$ pitch that is used in the thread tapping for the circular rods. For the modified circular rods with the diameters of 1.9, 1.94, and $2 \mathrm{~mm}$, the maximum principal stresses are 21000, 22900, and $30220 \mathrm{MPa}$, respectively.

Figure 10 shows the relationship between the friction factor and the maximum principal stress with different pitches of the circular rod. The maximum principal stress tends to increase with the increase in the friction factor. 


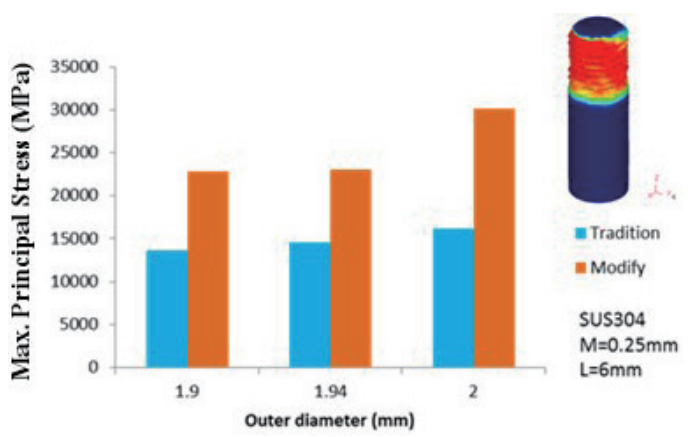

(a)

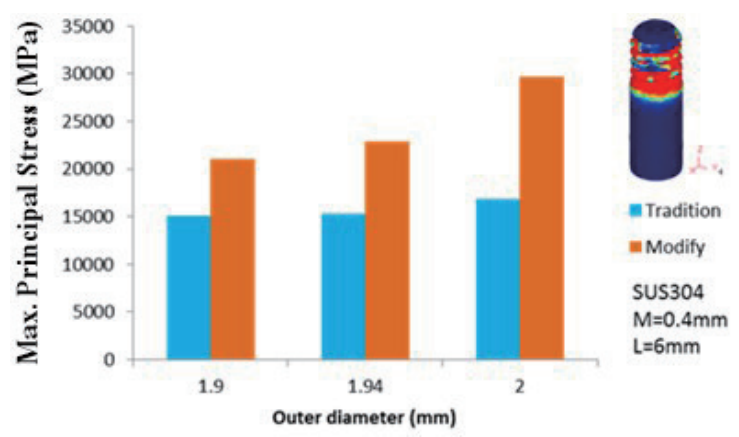

(b)

Fig. 9. (Color online) Relationship between outer diameter and maximum principal stress: (a) M2 $\times 0.25$ and (b) M2 $\times 0.4$.

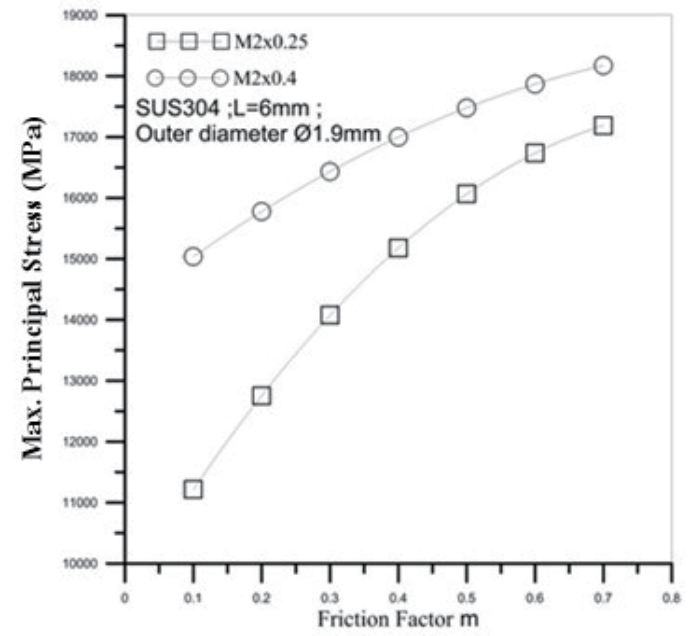

(a)

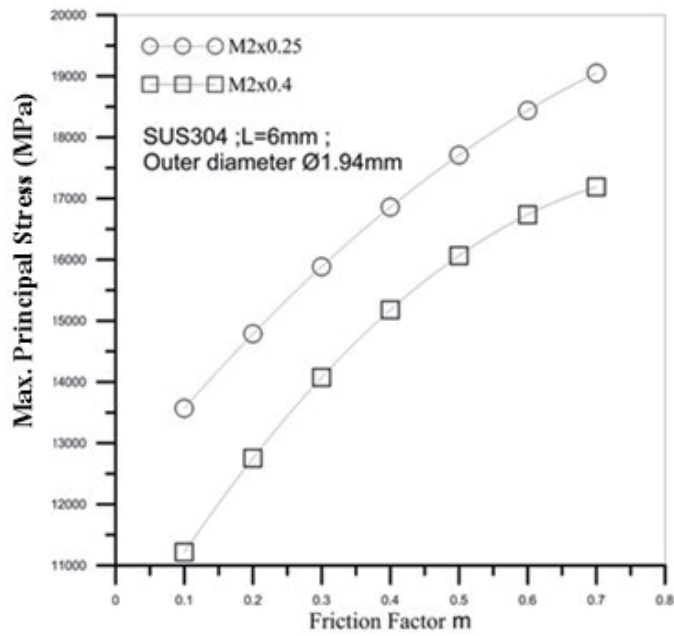

(b)

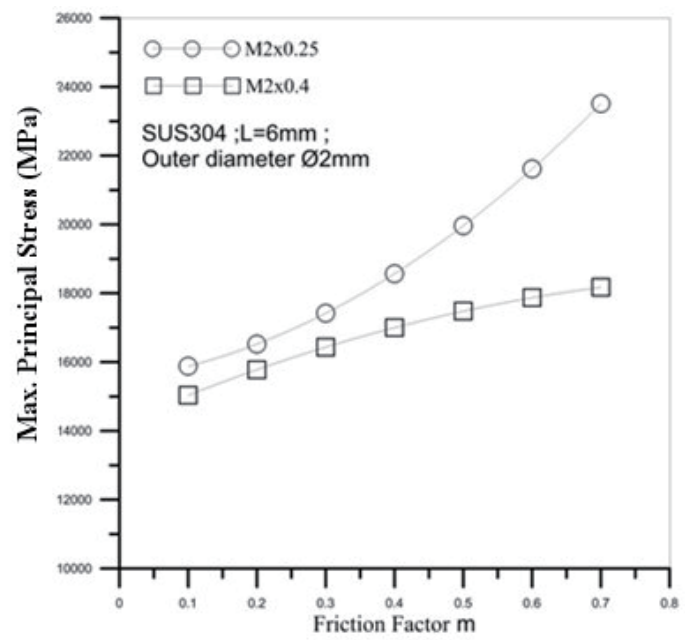

(c)

Fig. 10. Relationship between friction factor and maximum principal stress: (a) Ø1.9 mm, (b) Ø1.94 mm, and (c) $\varnothing 2 \mathrm{~mm}$. 
Figure 11 shows the relationship between the outer diameter of the circular rod and the maximum principal strain with two pitch values of the rod. The maximum principal strain increases with the increase in pitch. For M $2 \times 0.25$, the circular rods with the outer diameters of $1.9,1.94$, and $2 \mathrm{~mm}$ have the maximum principal strains of $0.672,0.725$, and $0.964 \mathrm{~mm} / \mathrm{mm}$, respectively, as shown in Fig. 11(a). For the pitch of $0.4 \mathrm{~mm}$, the rods with the outer diameters of $1.9,1.94$, and $2.0 \mathrm{~mm}$ have the maximum principal strains of $0.861,0.972$, and $1.45 \mathrm{~mm} / \mathrm{mm}$, respectively.

Figure 12 shows the relationship between the friction factor and the maximum principal strain. The maximum principal strain tends to increase with the increase in the friction factor. Results showed that the maximum principal strain is always greater for M $2 \times 0.4$ than for M $2 \times$ 0.25 at the same friction coefficient, but the influence of the outer diameter is minimal.

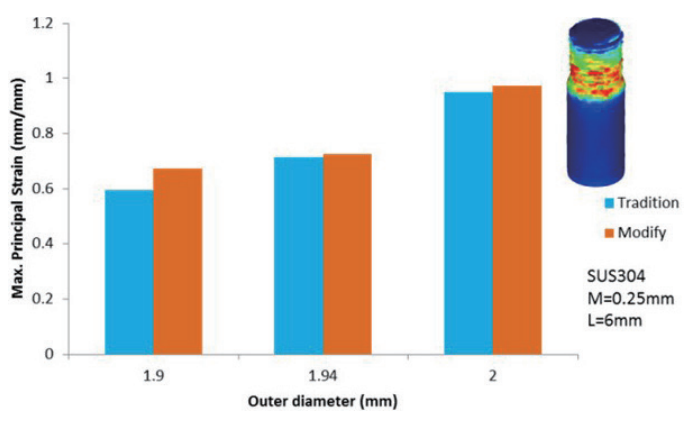

(a)

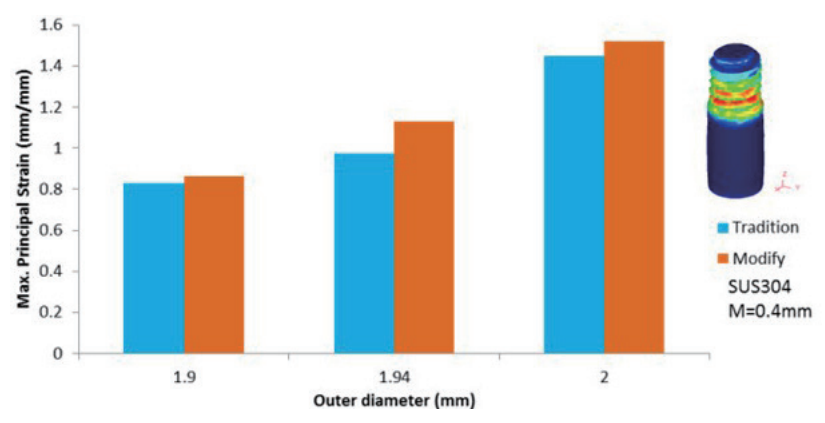

(b)

Fig. 11. (Color online) Relationship between outer diameter and maximum principal strain: (a) M2 $\times 0.25$, (b) M2 $\times$ 0.4 .

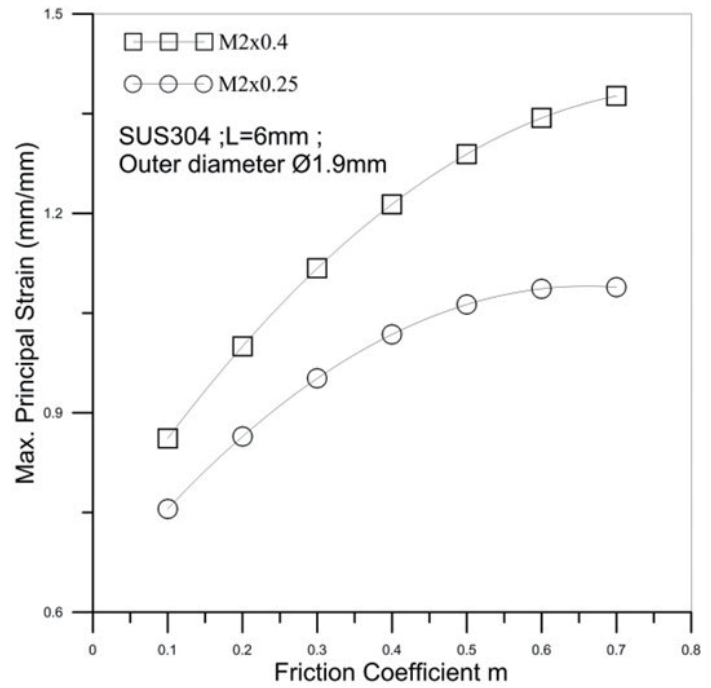

(a)

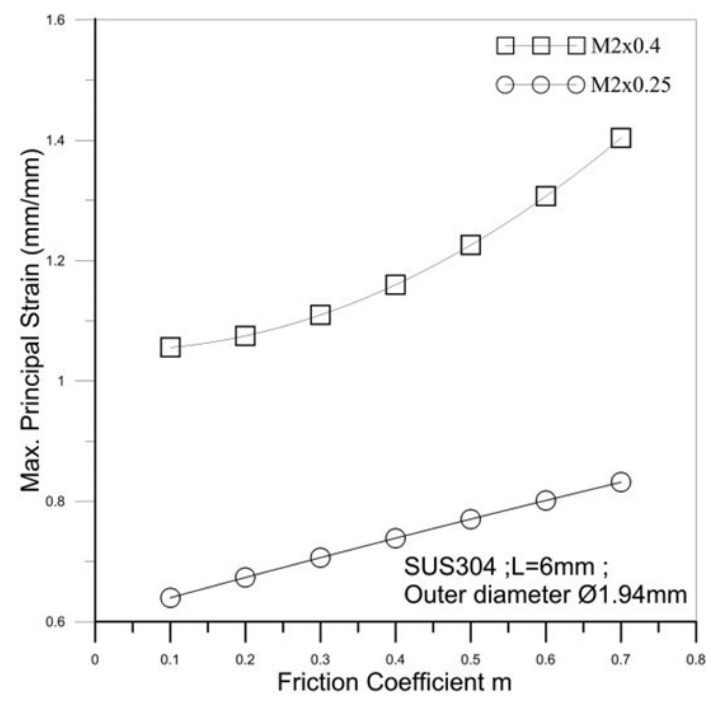

(b)

Fig. 12. Relationship between friction factor and maximum principal strain: (a) Ø1.9 mm and (b) Ø1.94 mm. 


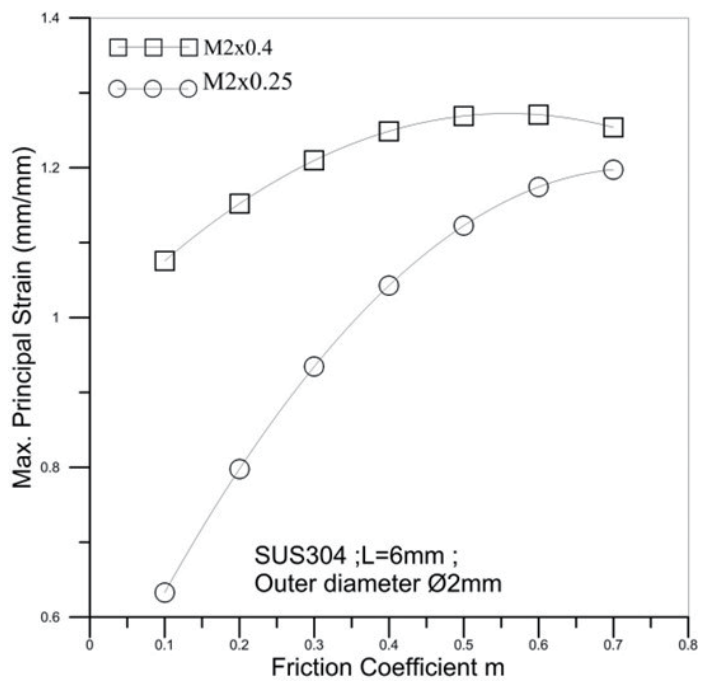

(c)

Fig. 12. (Continued) Relationship between friction factor and maximum principal strain: (c) Ø2 mm.

\section{Conclusions}

In this research, we used the SUS304 stainless steel circular rod as the material to proceed with the die fabrication and the thread tapping process. Two types of pitch were selected to compare the influences of the outer diameter of the circular rod and the friction factor on the product during the forming process. An optical microscope was also used to determine the tooth shape verified by the FE analysis, so the screw thread forming process could be accurately analyzed for the micro-type circular rods. Through the FE simulation and the comparison of traditional and modified models, the screw die torque was found to increase with the increase in the pitch for $\mathrm{M} 2 \times 0.4$. When the friction factors were changed during the screw thread machining process for the micro-type circular rod, the screw die torque increased with the increase in the friction factor. The maximum principal stress/strain tended to increase with the increase in the friction factor. Meanwhile, the maximum principal strain was always greater for $\mathrm{M} 2 \times 0.4$ than for M2 $\times 0.25$ at the same friction coefficient, but the influence of the outer diameter was minimal.

\section{Acknowledgments}

This research was funded by the Ministry of Science and Technology of Taiwan under grant numbers MOST 109-2221-E-167 -007, 110-2221-E-167-019, and 110-2622-E-167-008.

\section{References}

1 Y. Qin, A. Brockett, Y. Ma, A. Razali, J. Zhao, C. Harrison, W. Pan, X. Dai, and D. Loziak: Int. J. Adv. Manuf. Technol. 47 (2010) 821. https://doi.org/10.1007/s00170-009-2411-2 
2 M. W. Fu and W. L. Chan: Int. J. Adv. Manuf. Technol. 67 (2013) 2411. https://doi.org/10.1007/s00170-012-4661$\underline{7}$

3 A. Makinouchi and M. Kawka: J. Mater. Process. Technol. 46 (1994) 291. https://doi.org/10.1016/09240136(94)90117-1

4 U. Engel and R. Eckstein: J. Mater. Process. Technol. 125 (2002) 35. https://doi.org/10.1016/S09240136(02)00415-6

5 L. Peng, X. Lai, H. J. Lee, J. H. Song, and J. Ni: Mater. Des. 31 (2010) 1953. http://dx.doi.org/10.1016/j. matdes.2009.10.040

6 R. Chiba: Comput. Mater. Sci. 69 (2013) 113. https://doi.org/10.1016/J.COMMATSCI.2012.11.044

7 J. P. Domblesky and F. Feng: J. Mater. Process. Technol. 121 (2002) 341. https://doi.org/10.1016/S09240136(01)01223-7

8 Z. Pater, A. Gontarz, and W. Weroñski: J. Mater. Process. Technol. 153 (2004) 722. https://doi.org/10.1016/j. jmatprotec.2004.04.154

9 A. Gontarz, Z. Pater, and W. Weroñski: J. Mater. Process. Technol. 153 (2004) 736. https://doi.org/10.1016/j. jmatprotec.2004.04.164

10 Y. C. Kao, H. Y. Cheng, and C. H. She: J. Mater. Process. Technol. 177 (2006) 98. https://doi.org/10.1016/j. jmatprotec.2006.04.082

11 K. N. Huang: Study on Forging and Thread-rolling Processes of Magnesium Alloy Screws, National Sun Yat-sen University, Master's Thesis (2011).

12 Y. C. Li: Investigation of Tapping SUS 304 Using Micro-Taps, Ta Hwa University of Science and Technology, Master's Thesis (2014).

13 S. Pawar and S. S. Joshi: J. Manuf. Process. 22 (2016) 7. https://doi.org/10.1016/j.jmapro.2016.01.006

14 E. Oezkaya and D. Biermann: Int. J. Mech. Sci. 128 (2017) 695. https://doi.org/10.1016/j.ijmecsci.2017.04.011

15 G. L. Chern, Y. J. Wu, and S. F. Liu: J. Mats. Proc. Tech. 180 (2006) 102. https://doi.org/10.1016/j. jmatprotec.2006.05.010 